\title{
Laboratory Based Automatic Traffic Light Control System by Using (PLC) Programmable Logic Controller
}

\author{
${ }^{a^{*}}$ Mohsin Ali Koondhar ${ }^{1},{ }^{b}$ Masood Ali Koondhar ${ }^{2},{ }^{a}$ Ali Asif Malak ${ }^{1}$ \\ a: Department of Electrical Engineering, Quaid-e-Awam University of Engineering, Science and \\ Technology Nawabshah ${ }^{1}$ \\ b: Department of Electronic Engineering, Quaid-e-Awam University of Engineering, Science and \\ Technology Nawabshah ${ }^{2}$
}

\begin{abstract}
This research is focused on laboratory based analysis on hardware module of traffic light with Programmable Logic Controller (PLC) software. There are four ways in hardware model for detection of vehicle; each way has one sensor button, three Light Emitted Diodes (LEDs) with individual colors say red, yellow and green represents the traffic light in each lane. Sensor and LEDs are connected to Mitsubishi Programmable Logic Controller (PLC) and each part on hardware being controlled by PLC. Ladder diagrams are programmed by software to monitor the system and helps to improve public transportation services, thereby improving traffic guidance and traffic light control. The system was developed by setting the appropriate time for the traffic lights to respond accordingly. The controller checks the priority and provides an exit signal to the traffic light post to turn the red, yellow or green lights on or off. Finally, the signal lights were successfully controlled by the PLC. Hence the system used in traffic control systems contain low power consumption, low engineering cost and increased safety.
\end{abstract}

Keywords- PLC, traffic lights, ladder programming, sensor, PLC Interface Board

Date Received 30 Jan 2020

Date Accepted 28 Apr 2020

Date Published 25 June 2020

\section{INTRODUCTION}

$\mathrm{T}$ RAFFIC congestion has become a major problem restricting urban development [1]. The increase in congestion is due to insufficient traffic analysis and the use of time-limited traffic systems. The traffic lights used by the scheduled system will change color according to the time when the officials enter, which makes the traffic flow insufficient, because the traffic density is not considered when switching the walking time and the parking time [2].

In many cities of the world today, traffic congestion is a serious problem. Traffic jams have severely damaged emergency vehicles, especially ambulances. Every year, many patients die on the way to hospital due to time wasted due to traffic jams. Other emergency vehicles, such as firefighters and police patrols, also face difficulties in performing their tasks [3-6].

Due to industrialization and population growth, traffic management has become the most important aspect today, and traffic volume has also increased significantly. With the increase of traffic, serious traffic jams and violations of traffic rules have been occurred. Traffic congestion also causes long waiting time, wasted fuel and low productivity in the workplace. Therefore, it is necessary to establish an effective motion control system for social and economic aspects [7].
Nowadays, traffic jam became a big challenge in the world therefore it is necessary to introduce a traffic control system to be applied in cities with heavy traffic. To implement such a system, it must be implemented on a global scale throughout the city, and it is necessary to understand geographic factors, public road infrastructure, and daily / weekly methods $[8,9]$.

Traffic load depends to a great extent on parameters such as time, date, season, weather conditions and unexpected conditions (such as accidents, special events or construction activities). If these parameters are not considered, the traffic control system will cause bottlenecks and delays [10].

In order to realize the application of instructions, fire control and regulators need a certain level of intelligence. Conventional one-way traffic control system, from regulators to traffic lights [11].

PLC has high reliability, powerful anti interference capability, simple debugging, \& programming and propagation advantages. It has been broadly used in many areas of industry control. PLC has become one of the most important professional courses in application technology education [12, 13].

In conventional traffic control systems, it can be noted that the green light emission of a particular road is always constant. 
Sometimes it can happen that a particular road is more crowded than any other road. In this case, the traditional traffic control system will not be able to give priority to busy roads [14].

\section{PLC AS A SYSTEM CONTROLLER}

The PLC-based control system is a microprocessor based controller. In this a special programmable memory is used to store instructions \& various functions. A PLC is a type of functional computer used to complete the control and operation of a machine. It is programmable reserve, incremental guidance and completion (with $\mathrm{ON}$ and $\mathrm{OFF}$ ) function [15].

The term logic is used because programming involves essentially applying logic and switching operations. The operator then enters multiple instructions (i.e programs) into the PLC's memory. The controller then monitors inputs and outputs according to the program and executes programmed control rules for it. Operators only need to type a different set of instructions to modify the control system and rules of use. no rebuilding is needed [16].

\section{PROBLEM STATEMENT}

Monitoring of city traffic lights has become major issue in multiple countries. The increase in the no. of vehicles \& the development of low-level highway have caused traffic jam, curiously in large cities like Karachi, Hyderabad, Sukkur, Multan and Lahore, etc. These are adversely affected by traffic, travel time, environmental standards, quality of life and road safety. In addition, traffic delays indirectly affect productivity, efficiency, and power loss. There are many factors such as the density of vehicles on the road that cause traffic congestion, people's lifestyle, and social behavior and traffic lights systems.

One of the main issues is traffic control at the intersection by the traffic light system. Traffic police are setup in traffic lanes frequently to overcome traffic jam at the time of rush hour, so major causes of problem is the inefficiency of traffic light controllers. By effectively controlling the intersections, it is considered that overall efficiency \& performance of the urban transport network can be targeted. There are several traditional ways to control traffic lights, but they cannot effectively handle complex traffic conditions and can change over time. Currently, traffic light control devices are usually installed in Pakistan and many places around the world. Obviously, given the large number of traffic police operating in cities during peak hours, supervision of these traffic lights is insufficient. There is a need for a new efficient and practical traffic light controller.

\section{PROPOSED METHODOLOGY}

To solve this traffic problem, a PLC based controller is proposed to overcome this major problem. To that end, traffic signal control module is introduced at crossroads with crosswalks for an interactive simulation of traffic and pedestrian control light signals. It is designed to control by set of PLC to monitor and control its external affairs. Proposed system divided into five main parts-:

- Hardware Model.

- PLC Interface module.

- PLC.

- Programming software.

- Ladder logic Programming.

\section{A. Hardware Model}

The hardware model includes a screen-printed panel depicting an intersection with a crosswalk, which is equipped with colorful lights that represent the typical traffic control signal. Three lights on the north and south, three lights on east west road \& 2 lights on the crossing of pedestrian, making total of 8 lights are controlled by PLC. The panel also has five buttons installed, which can mimic the detection of a vehicle by pressing four buttons on any one of the 4 traffic sensors or simulating pedestrians request for an intersection. It is an idea to control by multiple PLCs for monitoring and controlling external objects. Crossroads simulation with glass fiberboard, crosswalk and traffic control signals as shown in figure 1.

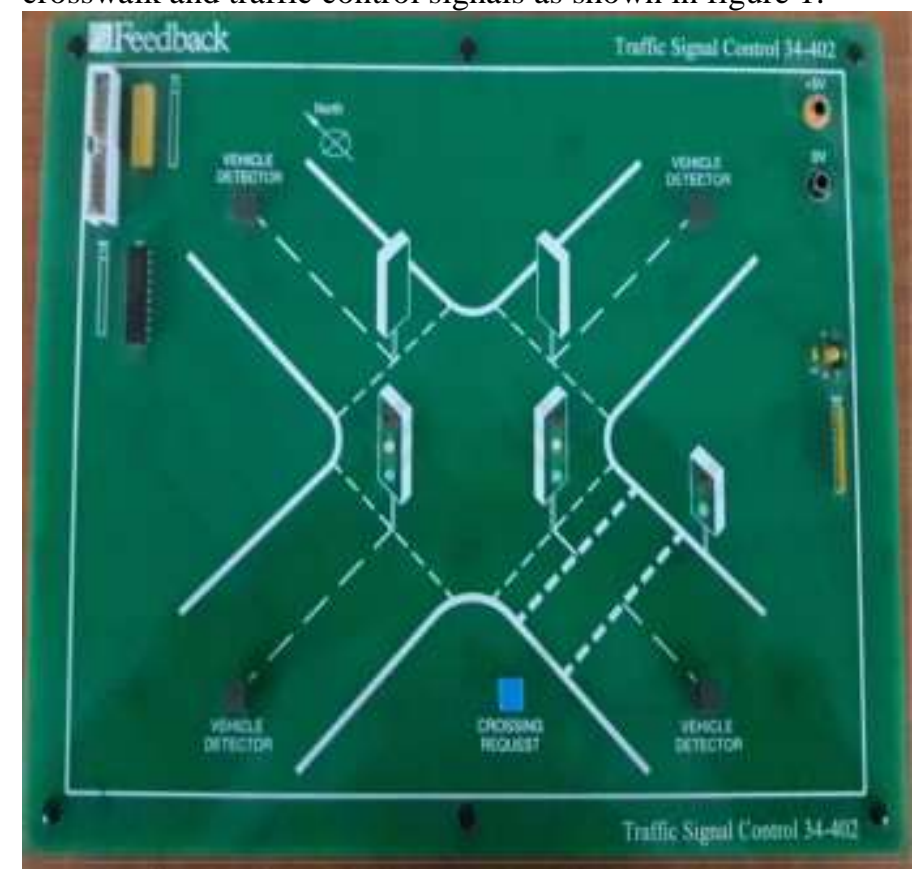

Figure 1: Traffic Light Hardware Model

\section{B. PLC Interface module}

This cable provides a way for all necessary connections to the PLC. A connector for receiving a ribbon cable from PLC Interface and a box with a screw-in terminal to receive the connection cable from selected PLC. The PLC $24 \mathrm{~V}$ DC line is used to supply the $+5 \mathrm{~V}$ DC power required by the traffic 


\section{DOI: https://doi.org/10.36785/BUITEMS.JAES.352}

signal module in $4 \mathrm{~mm}$ socket. The actual connection to the PLC can vary depending on the manufacturer and model of

the PLC used.

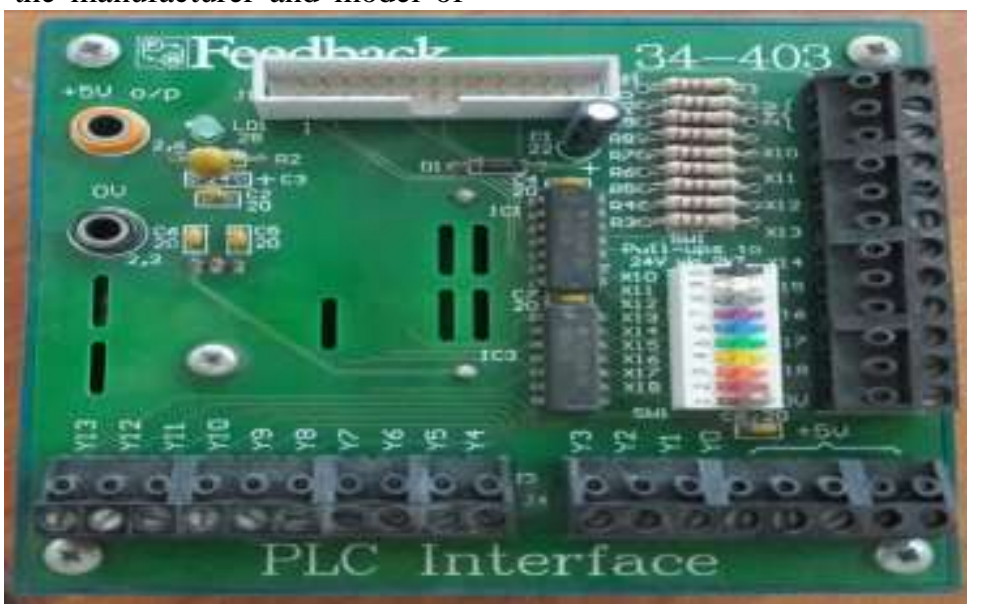

Figure 2: PLC Interface Module

\section{RESULT AND DISCUSSION}

Instruction, time duration, PLC ladder logic and flowchart were generated in GX-Developer Software to control traffic lights. Experimental setup of Traffic signal control with PLC is shown in figure 3.

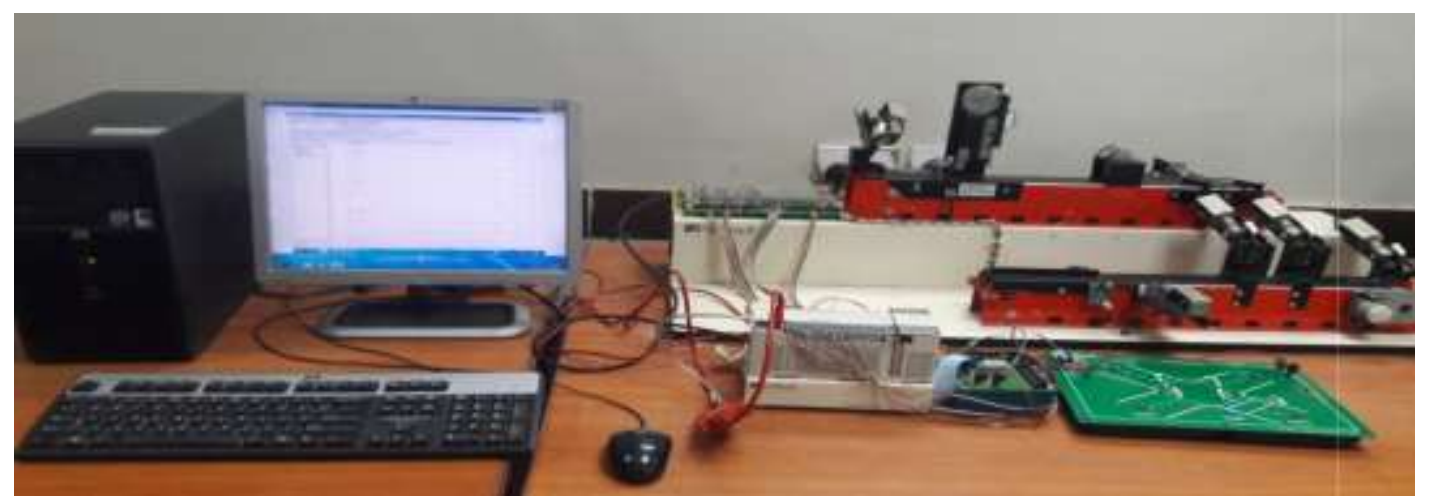

Figure 3: Experimental setup of Traffic signal control with PLC

Equivalent circuit of traffic signal control and PLC Interface are presented in figure 4 and 5, whereas flowchart and ladder logic are presented in figures 10 and 11 respectively.

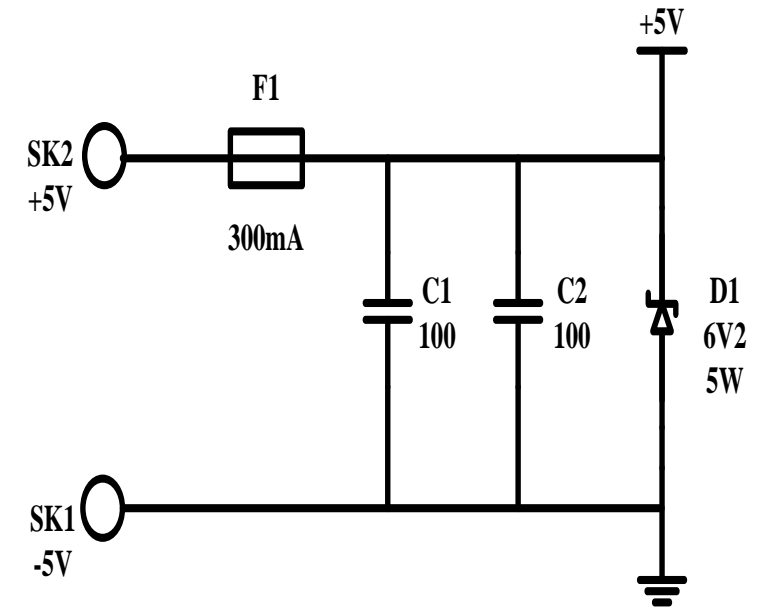

Figure 4: Traffic Signal Control Equivalent Circuit

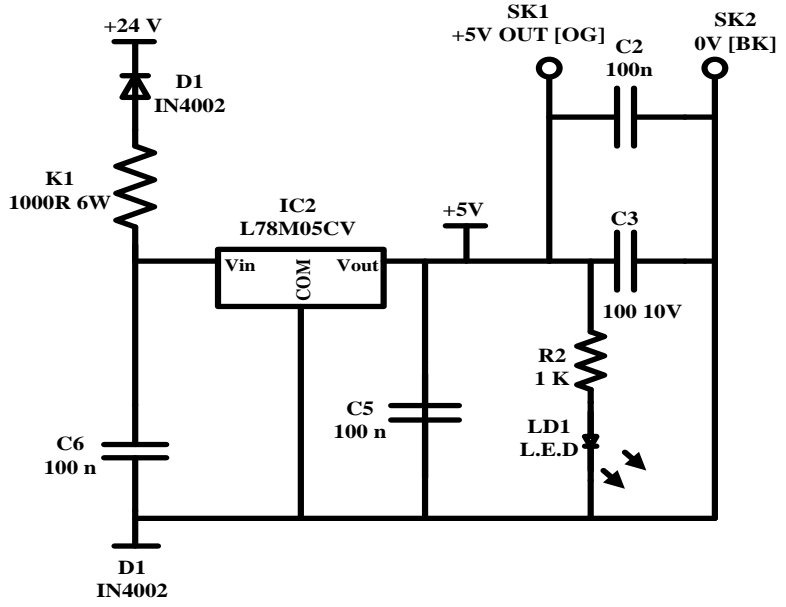

Figure 5: PLC Interface Equivalent Circuit

\section{A. South / North Switch Pressed}

Journal of Applied and Emerging Sciences Vol (10), Issue (01) 


\section{DOI: https://doi.org/10.36785/BUITEMS.JAES.352}

Table 1 shows the south/north switch press for detecting the vehicles. There is a Pedestrian is also available for crossing the road from one side to another.

Table 1: South/North switch press.

\begin{tabular}{|c|c|c|c|l|}
\hline Line & Pedestriàn & $\begin{array}{c}\text { South } \\
\text { North }\end{array}$ & Tíme ( sec) & Sequence \\
\hline 1 & Ŕed & $\begin{array}{c}\text { Red } \\
\text { Ámber }\end{array}$ & 1 & \multirow{2}{*}{$\begin{array}{l}\text { South } \\
\text { North }\end{array}$} \\
\cline { 1 - 4 } 2 & Ŕed & G̣reen & 6 & \\
\cline { 1 - 4 } 3 & Ŕed & Åmber & 3 & \\
\cline { 1 - 3 } 4 & Ŕed & Ŕed & 1 & \\
\hline
\end{tabular}

Figure 6 illustrates that four different path on which different lights are shown, the red light indicate stop, green light shows the flow of traffic and amber light performs a very necessary function to the safety of the intersection. Amber light is a transition period between stop and go. Red and amber signal means stop for $1 \mathrm{sec}$. Do not start until green shows. Green shows vehicle and pedestrian can move from its position. This time, the east and west and cross signals are red.

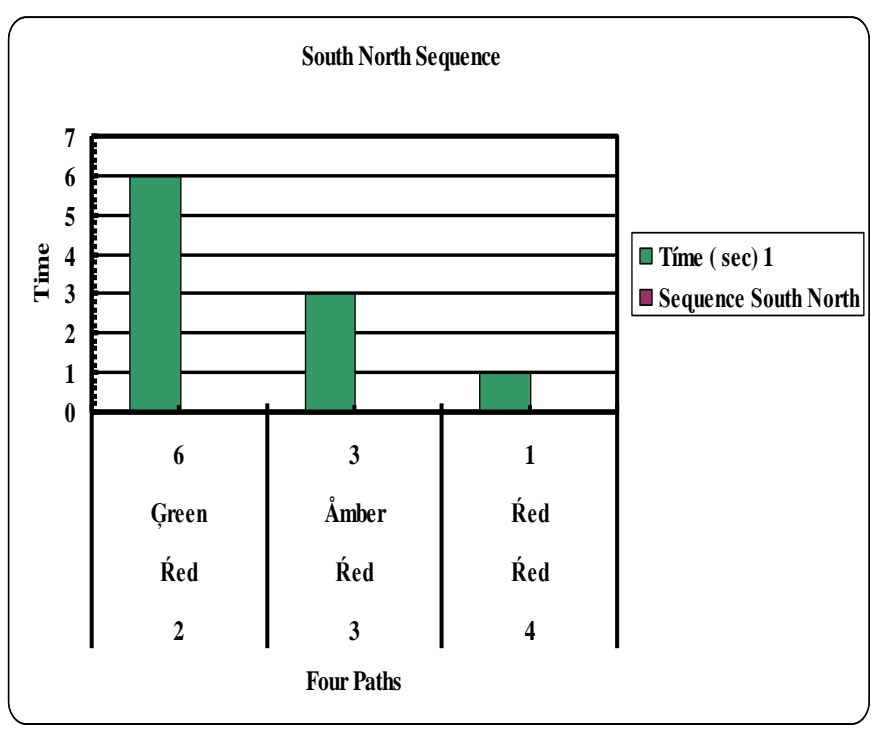

Figure 6: South North Sequence

\section{Pedestrian Request}

Table 3 shows the pedestrian request on different paths to cross the road.

\section{B. East / West Switch Pressed}

Table 2 represents the east / west switch press for detecting the vehicles.

Table 2: East/West switch press.

\begin{tabular}{|c|c|c|c|c|}
\hline Line & Pedestriàn & East Wëst & Tíme ( sec) & Sequence \\
\hline 1 & Red & $\begin{array}{l}\text { Réd } \\
\text { Åmber }\end{array}$ & 1 & \multirow{4}{*}{$\begin{array}{l}\text { East } \\
\text { Wëst }\end{array}$} \\
\hline 2 & Ŕed & G̣reén & 6 & \\
\hline 3 & Ŕed & Åmbér & 3 & \\
\hline 4 & Ŕed & Réd & 1 & \\
\hline
\end{tabular}

Figure 7 shows that east west pressed. When vehicle travel from east west but the pedestrian can walk from south north side. If the red light is turned ON 1 second in east west side then the pedestrian can walks through that path and vice versa. This time, the south and north and cross signals are red.

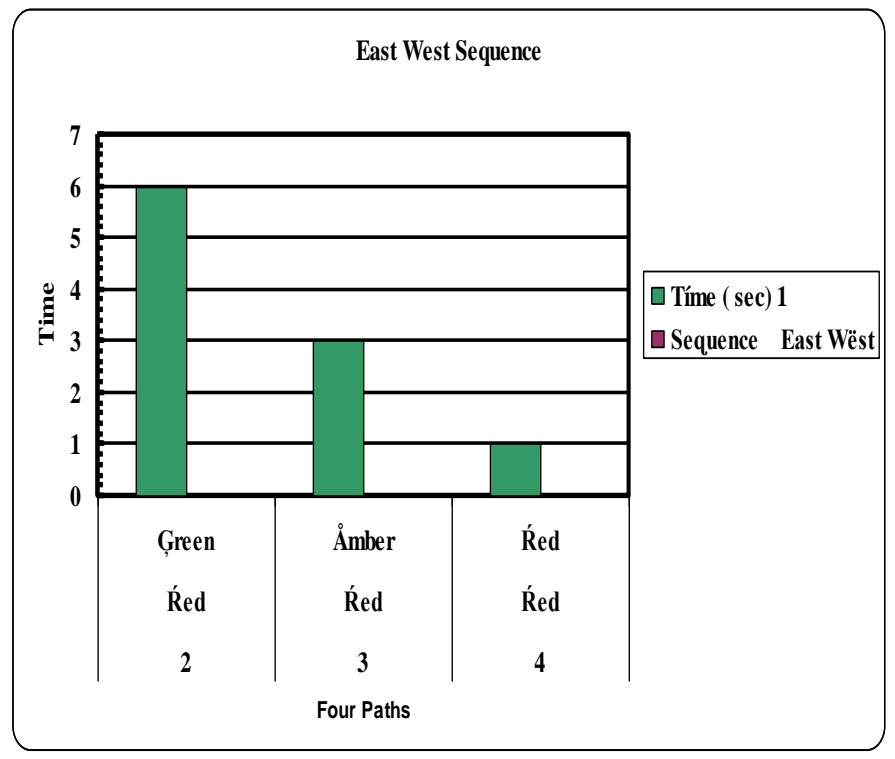

Figure 7: East West Sequence 
DOI: https://doi.org/10.36785/BUITEMS.JAES.352

Table 3: Pedestrian switch press

\begin{tabular}{|c|c|c|c|c|c|}
\hline Line & Pédestriàn & South North & East Wést & Tíme ( sec) & Sequence \\
\hline 1 & Réd & Rëd & Ŕêd & 0 & \multirow{4}{*}{ Péđestriàn } \\
\hline 2 & Ģreen & Ŕëd & Rêed & 6 & \\
\hline 3 & Rëd & Rëd & Rêd & 0 & \\
\hline 4 & Rëd & Rëd & Rêd & 1 & \\
\hline
\end{tabular}

Figure 8 states that when a request from a pedestrian arrives and the system is not in initial state, this means that the operation is performed with a north / south or east / west signal, and then the request will be saved by the system and executed after a delay until the system enters the initial state. If the system currently works on the East / West or North / South semaphores and faces pedestrian requests, the system requested by the pedestrian and the system requested for changes will be saved. After performing the full sequence of signals, the system will reach the initial state (i.e. all signals are lit in red), the pedestrian signal turns red, \& green-light goes $\mathrm{ON}$ for $6 \mathrm{sec}$.

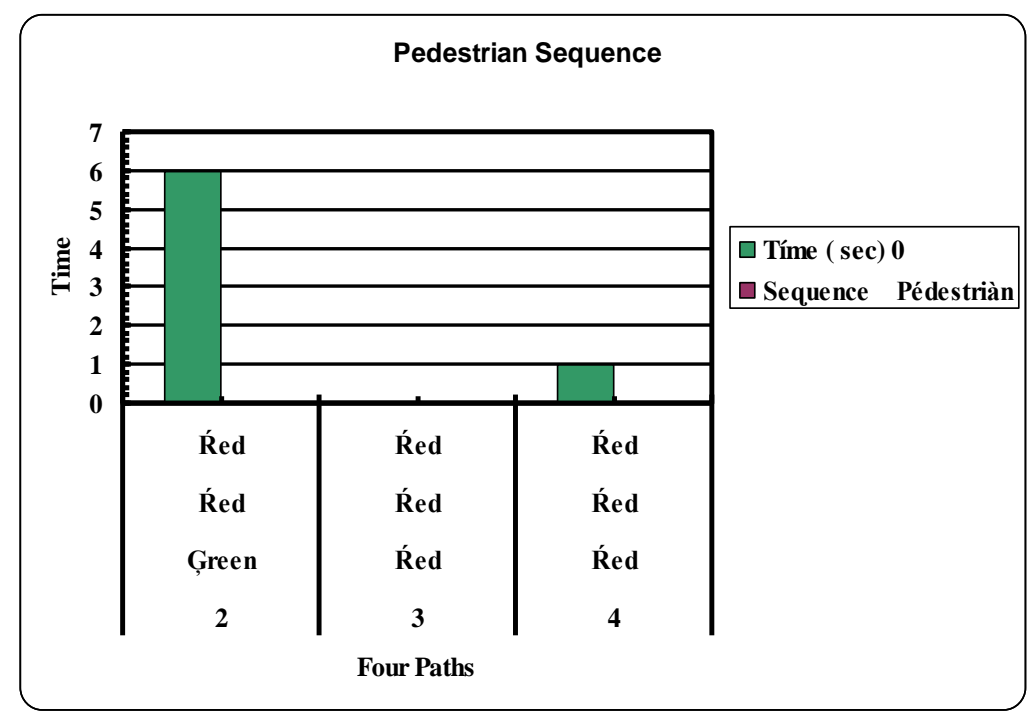

Figure 8: Pedestrian Sequence

Comparison of integrated result for traffic light control system for four paths with pedestrian is shown in table 4 .

Table 4: Comparison of Integrated Result for Traffic-Light Control

\begin{tabular}{|c|c|c|c|c|c|}
\hline Lines & Pédestriàn & East Wést & South North & Tíme ( sec) & Śub-Sequence \\
\hline 0 & ŔËD & ŔËD & ŔËD & 0.0 & \multirow[t]{4}{*}{ Peđeśtrian } \\
\hline 1 & Green & ŔËD & ŔËD & 6.0 & \\
\hline 2 & ŔËD & ŔËD & ŔËD & 0.0 & \\
\hline 3 & ŔËD & ŔËD & ŔËD & 1.0 & \\
\hline 4 & ŔËD & ŔËD Åmbër & ŔËD & 2.0 & \multirow[t]{4}{*}{ East Ŵ́sţ } \\
\hline 5 & ŔËD & Green & ŔËE & 6.0 & \\
\hline 6 & ŔËD & Åmbër & ŔËD & 3.0 & \\
\hline 7 & ŔËD & ŔËD & ŔËD & 1.0 & \\
\hline 8 & ŔËD & ŔËD & ŔËD Åmbër & 1.0 & \multirow[t]{4}{*}{ South North } \\
\hline 9 & ŔËD & ŔËD & G̣reen & 6.0 & \\
\hline 10 & ŔËD & ŔËD & Åmbër & 3.0 & \\
\hline 11 & ŔËD & ŔËD & ŔËD & 1.0 & \\
\hline
\end{tabular}


Figure 9 illustrates Comparison of Integrated Result for Traffic-Light Control for four directions east west south north with vehicle and pedestrian. Pedestrian can move its position for 6 second, at line 4 (east west) pesdestrian / vehicle can wait 2 seconds until green light turn ON, as soon as green light gets turned ON its can moves from one side to another side of road. Same condition is in line 8 (south north) wait for 1 second for green turn ON.

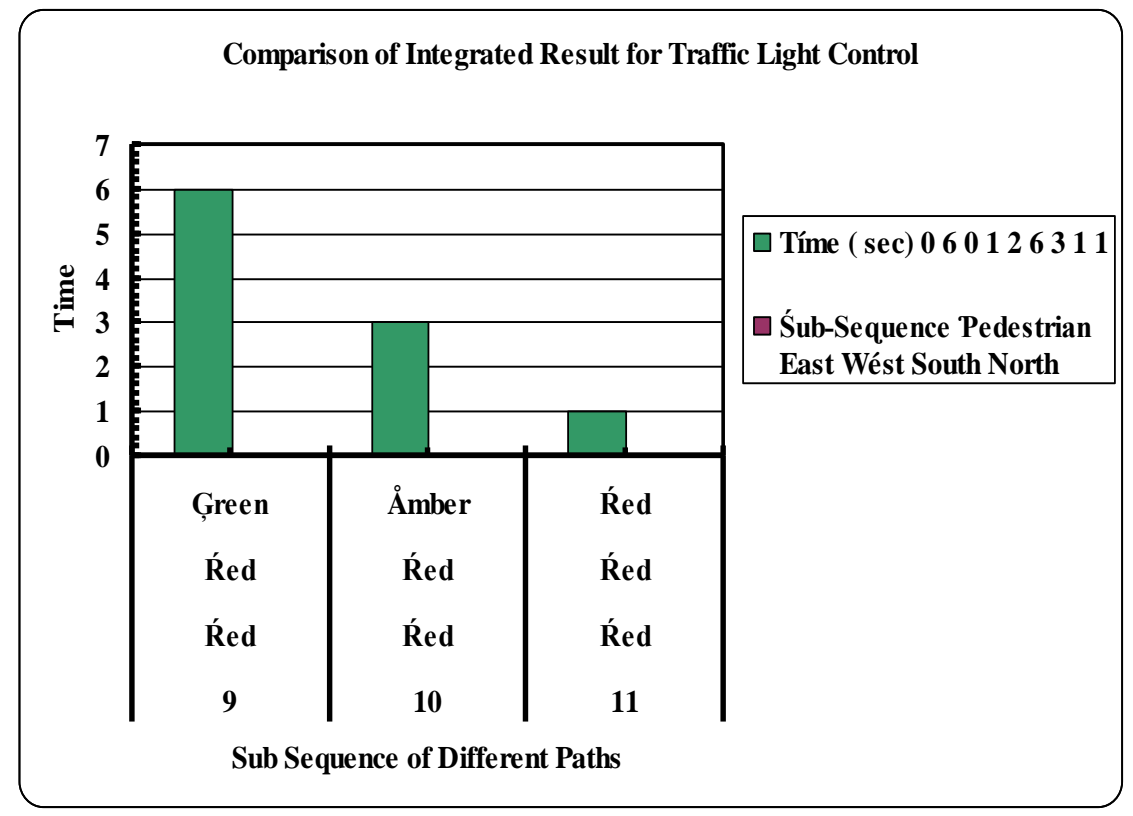

Figure 9. Integrated Result for Traffic Light Control

\section{CONCLUSION}

With the help PLC programming traffic control system is done in QUEST Laboratory. A simple sequential PLC application allows the control of traffic lights at intersections on the basis of a timed sequence. Control procedures can be developed to manage interruptions caused by requests for pedestrian crossings or inputs from off-peak vehicle detectors. The pedestrian's green light is only activated when certain inputs are activated. In our case, there is a button labeled and located near the crosswalk so that those who wish to cross the intersection can make this request. Since heavy and light vehicles will operate on different lanes, this approach will help reduce road congestion $\&$ deal with accidents. As a result, using this system can solve the problem of traffic and fatal accidents. Thus, the proposed system will provide us with a safe travel route. 


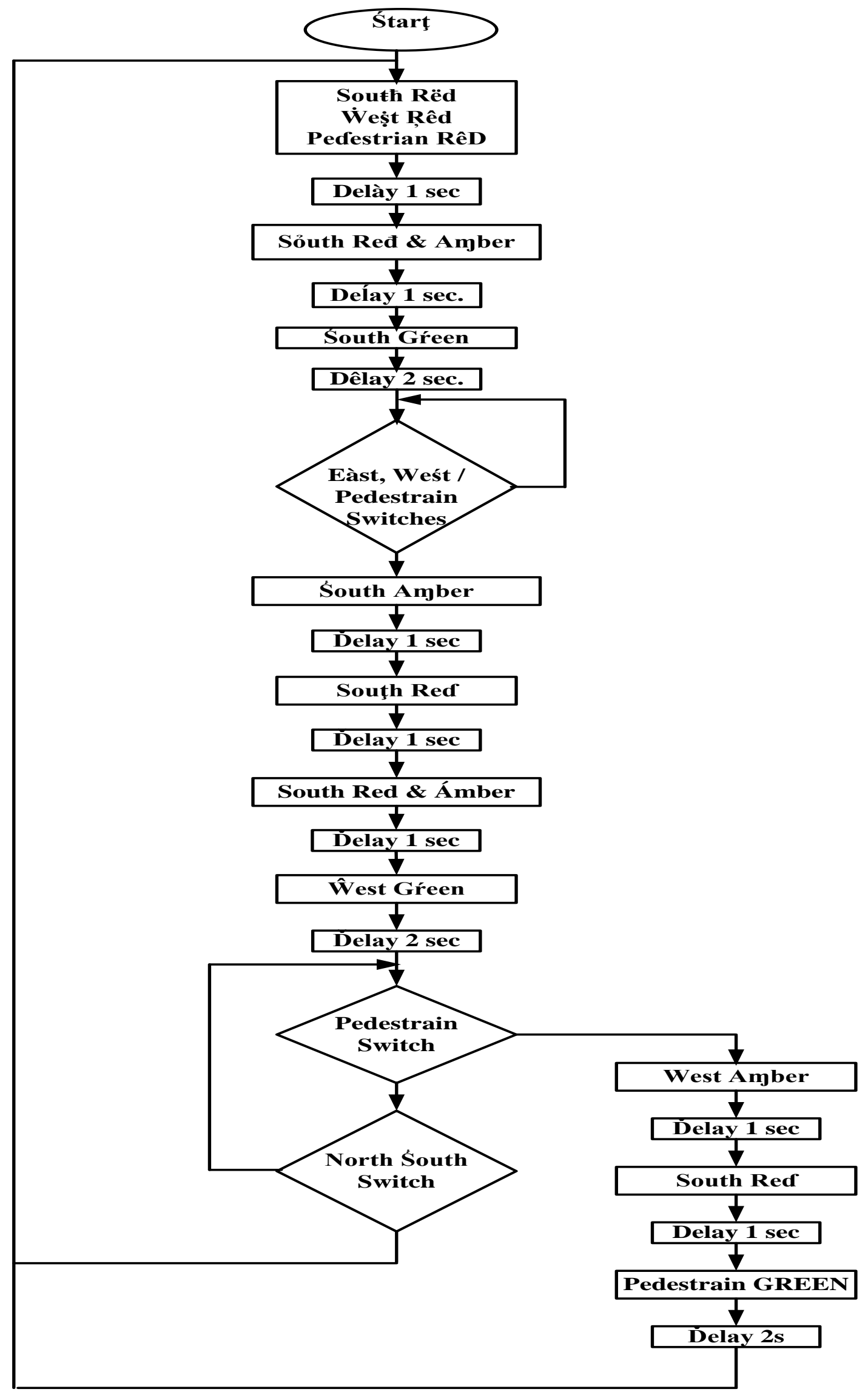

Figure 10: Flowchart of Traffic Light Control 

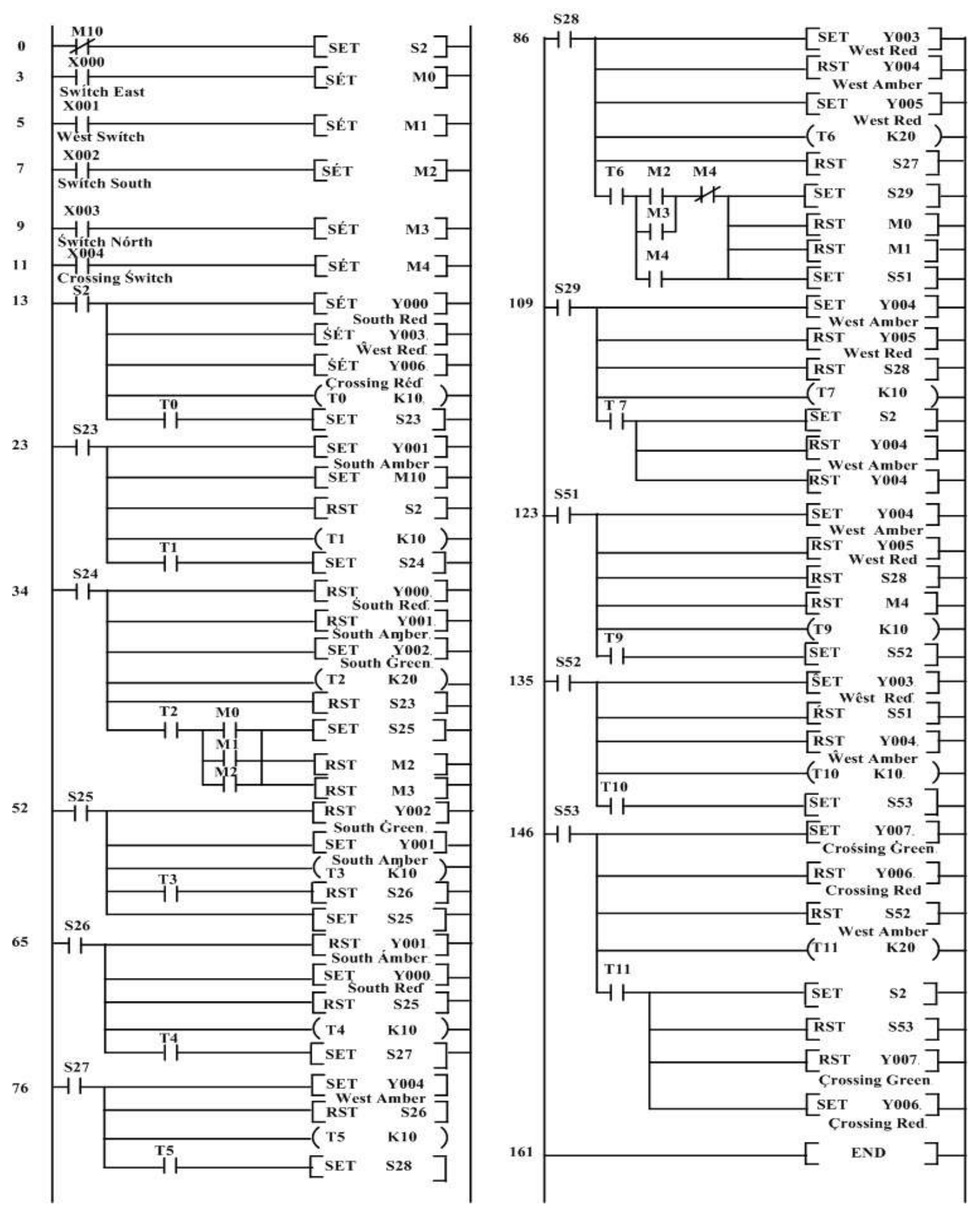

Figure 11: Ladder Logic of PLC 


\section{REFERENCES}

[1] L. Mei, Z. Lijian and W. Lingling, "Intelligent Traffic Light Based on PLC Control," In IOP Conference Series: Earth and Environmental Science, vol. 94, no. 1, pp. 012073, 2017.

[2] K.A.C. Basconcillo, D.J.B. Benitez, E.A.S. Cantuba, R.E. L. Enriquez, C.R.I. Falcon, K.K.D. Serrano, E.C. Guevara, A. R.D. Cruz, and R.R.P. Vicerra, "Development of a Vehicle and Pedestrian Simulation Environment with M.I.S.O. Fuzzy Logic Controlled Intelligent Traffic Light System," $5^{\text {th }}$ IEEE International Conference on Information and Communication Technology, pp. 1-6, 2017.

[3] S. Amir, M.S. Kamal, S.S. Khan and K.M.A Salam, "PLC Based Traffic Control System with Emergency Vehicle Detection and Management," IEEE International Conference on Intelligent Computing, Instrumentation and Control Technologies, pp. 1467-1472, 2017.

[4] S. V. Viraktamath, P. Holkar, P. V. Narayankar, and J. Pujari, "Adaptive Intelligent Traffic Control System using PLC," International Journal of Innovative Research in Computer and Communication Engineering, pp. 287-290, 2015.

[5] C. Barz, C. Todea, T. Latinovic, D. M. Preradovic, S. Deaconu, and A. Berdie, "Intelligent traffic control system using PLC," IOP Conference Series: Materials Science and Engineering, vol. 144, pp. 1-7, 2016.

[6] T. Osman, S. S. Psyche, J. M. S. Ferdous, and H. U. Zaman, "Intelligent traffic management system for cross section of roads using computer vision," $7^{\text {th }}$ IEEE Annual Computing and Communication Workshop and Conference (CCWC), 2017.

[7] S. Naveen, B. Deepika, S. Rekha, P. Kantam and B. K. Banga, "Smart Traffic Control System using PLC and Raspberry Pi," International Journal of Innovative Research in Computer and Communication Engineering, vol. 6, no. 3, 2018.

[8 ] S.V. Kishore, V. Sreeja, V. Gupta, V. Videesha, I. B. K. Raju and K.M. Rao, "FPGA based Traffic Light Controller," IEEE International Conference on Trends in Electronics and Informatics,Tirunelveli, India, pp. 469475, 2017.

[9] C. Barz, C. Todea, T. Latinovic, D.M. Preradovic, S. Deaconu and A. Berdie, "Intelligent traffic control system using PLC," In IOP Conference Series: Materials Science and Engineering, vol. 144, no. 1, pp. 012017, 2016.

[10] S. Kumari and S. Kumari, "Traffic Control System using PLC," International Journal of Engineering Science and Computing, pp. 9978-9981, 2017.

[11] P. Sharma and A. Goen, "Smart Traffic Control System Using Weighted Data," International Journal of Advance Research in Science and Engineering, vol. 7, no. 6, 2018.

[12] H. Wang, J. Lu, W. Li, and Z. Jiang, "Development of three dimensional virtual PLC experiment model based on Unity3D," IEEE First International Conference on Electronics Instrumentation \& Information Systems, pp. $1-4,2017$.

Journal of Applied and Emerging Sciences Vol (10), Issue (01)
[13] Q. Yuan, X. M. Liu, and X. L. Yi, "Research and Practice on the teaching reform of PLC application technology," Education and Teaching Forum, no. 4, pp. 122-124, 2015.

[14] S. V. Viraktamath, P. Holkar, P. V. Narayankar, J. Pujari, "Adaptive Intelligent Traffic Control System using PLC," International Journal of Innovative Research in Computer and Communication Engineering, vol. 3, no. 1, pp. 287290, 2015.

[15] M. A. Koondhar, A. K. Junejo, A. S. Saand, and M. U. Keerio, "Speed Control of DC Series Motor with Conventional and PLC Techniques," International Journal of Information Technology and Electrical Engineering, vol. 5, no. 4, pp. 21-26, 2016.

[16] Mitsubishi Fx Programmable Logic Controllers, $2^{\text {nd }}$ Ed. Applications and Programming Feedback Company UK (Lab Manual).

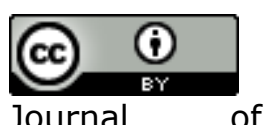

Applied and Emerging Sciences by BUITEMS is licensed under a Creative Commons Attribution 4.0 International License. 